\title{
Laparoscopy and litigation: small access, small injuries, big trouble
}

\author{
D Bass \\ Medico-legal Unit, Western Cape Provincial Department of Health, South Africa
}

Corresponding author,email:dbass@global.co.za

The refinement of optic technology and the commercial availability of laparoscopic hardware in the later part of the 20th century were warmly welcomed by innovative specialists who operated on the abdomen or pelvic cavity. The advantages of minimal access, negligible scarring and shorter recovery time promised higher patient satisfaction and lower hospital costs as well as a tangible sign of surgery taking yet another exciting step into the age of 'hi-tech'. Many surgeons may also have anticipated shorter operating time, particularly when confronted with obese patients, and some of them would have been right - assuming all went well.

As would be the case with any procedure or newly adopted therapy, thirty-odd years of global experience with laparoscopy has been instructive, and some lessons learnt have been more sobering than others. Laparoscopic cholecystectomy for example, carries a $0.3-0.6 \%$ risk of iatrogenic bile duct injury (BDI) ${ }^{1}$ that in turn may result in a harrowing (for patient and injuring surgeon alike) sequence of diagnostic, drainage and reconstructive procedures. This unfortunate but well-recognised morbidity following laparoscopic cholecystectomy remains stubbornly consistent, ${ }^{1,2}$ and one of the most frequent sources of medical malpractice litigation against general surgeons. ${ }^{2}$ This is hardly surprising in view of the reported $10-25 \%$ long-term morbidity associated with laparoscopic BDI. In an economically distressed developing country such as the Republic of South Africa, unanticipated hospital costs, depletion of medical insurance benefits, lost time in the workplace and possible loss of employment create significant financial stressors for which litigation may be sought as the only effective remedy.

Meanwhile, the litigation industrial complex in South Africa has burgeoned over the past 2 decades, ${ }^{3}$ fuelled both by legislation which encourages attorneys to accept cases on contingency, ${ }^{4}$ and by increasingly higher settlements or awards handed down by the courts to successful plaintiffs. An additional driver for this state of affairs has been profound disenchantment with the meagre awards available from a chronically unstable and bankrupt Road Accident Fund, diverting increasing numbers of personal injury specialists towards the far more lucrative medical malpractice litigation. In this writer's personal experience of litigation against state hospitals, settlements of indefensible claims arising from laparoscopic BDI tend to be in the region of R4 000000 excluding legal costs, but the sums may be considerably higher when these injuries are sustained by private patients. ${ }^{5}$

Surgeons are technical beasts by nature; when any nature of complication occurs, and we sit down to review our actions, our primary focus will inevitably be on operative detail. In the case of laparoscopic BDI, the complexity and variability of sub-hepatic anatomy, particularly within the margins of Calot's triangle, will be re-run over and over in our minds and more often than not, without any clearly specific reason identified for the mistake that caused injury. However, from this writer's (admittedly unfair) privilege of reviewing hundreds of medical negligence lawsuits, the injured patients perspective, and the motivations which drive them towards an attorney's office are often far less concrete, and inevitably more diverse than simply the injury itself. We need to try and see the complication and its implications through the patients' eyes in order to gain some insight into how we can limit the risks of litigation following iatrogenic BDI.

\section{One opportunity for first impressions}

I staunchly believe that a patient who likes and trusts their surgeon is less likely to litigate than one who feels disaffected, ignored or confused. This is not to say that a good doctor-patient relationship alone will prevent litigation after iatrogenic BDI. Rather, I base my viewpoint on the large number of patients I have encountered whose interest in litigation seems to be driven more by enmity than by economic factors, and often a gnawing desire for retribution. When I encounter this attitude, I always wonder when and how the relationship broke down, or it if was ever properly established in the first place.

The "power differential" between doctors and patients is by no means a thing of the past, and to level it, the onus rests on the medical practitioner to express genuine care, concern, respect and even humility from the first contact. To listen with interest, to maintain eye contact, to avoid the distraction of the ubiquitous desktop computer, and to make as much time to clerk, clinically assess and counsel each individual patient as required may sound like a tall order. Granted, time is both precious and pressured, and there may be tetchy sounds coming from the waiting room. But consider the real possibility that 10 extra minutes in your consulting room may obviate a monkey on your back for 3-5 years (the average time taken to settle or defend a medical negligence lawsuit), and two soul-sapping days in the witness box. Seen that way, those 10 extra minutes are clearly a blue-chip investment.

When the diagnosis of symptomatic cholelithiasis clearly demands surgery, most surgeons will abide by the ritual of obtaining informed consent, each doctor initiating and completing this process in an individual way. To most modern-day surgeons, a well-rehearsed presentation of method, benefits, risks, complications and the possible need for blood products culminating in a signature on a proforma 
consent form is sufficient, and in keeping with his/her statutory obligations. ${ }^{6}$ Or is it?

Most adult patients confront the prospect of surgery with trepidation, subjective perception, idealised expectation and random bytes of information harvested from the internet. On the other hand, the basket of medical facts offered before soliciting their consent to surgery, or even that set out on a 'take-home' information sheet, tells them what we as surgeons believe they ought to know, but may not address the questions and concerns which each individual harbours. Given the appropriate time and atmosphere to speak up, the most urbane patient may express fears which vary from the banal to the frankly bizarre; "Will I still be able to eat snails because I absolutely love snails au gratin?"; "How soon can I start playing golf?"; "I read about someone who woke up in the middle of the anaesthetic...". These seemingly trivial thoughts may appear on the surface to be of overblown concern but are more likely an abstract expression of bewilderment or apprehension which the patient is too embarrassed to voice. Responding in an empathetic and respectful manner will build trust and cement a healthy therapeutic relationship for the knock-down price of a few extra minutes.

For many patients, repetition of facts, precautions and reassurances are indispensable: Like the video safety drill trundled out each time you fly on a commercial airliner, you accept that the content is important, but it's too much to remember (so you don't) and sudden depressurisation of the cabin probably won't happen anyway (until it does). So it goes with presurgical counselling. If your patient develops that glazed stare into the middle-distance while you are speaking, best to take a deep breath and start again.

The main point to be made is that our tight focus on informed consent should really be teased out into a broader preoperative counselling session, and in the case of elective surgery, possibly a follow-up session for patients who seem excessively anxious. If issues are raised which cannot be recorded on a printed informed consent proforma, supplementary notes in the patient file are well-advised, and may be your best available defence in the event of future litigation. This may be particularly appropriate in the case of patients with a higher risk profile, e.g. the elderly, those with multiple documented attacks of acute cholecystitis, or those with a history of bile duct stones.

In a review of 113 medico-legal files originating from laparoscopic BDI, De Reuver et al. ${ }^{7}$ found documentary evidence of informed consent in only $23 \%$ of cases and detail of the actual informed consent discussion in $11.5 \%$ on file. The association between such nonchalance and legal consequences is obvious.

\section{The procedure}

It is well beyond the scope of this opinion piece - not to mention the relative lack surgical expertise of the author - to discuss the technical aspects of iatrogenic BDI, and I am aware that these aspects are well covered by local experts in this issue and by the copious literature on the subject.

However, I will reprise the time-honoured advice to document the procedure legibly, in appropriate detail, and include a clear written plan for postoperative care. After complicated procedures, additional detail about technical challenges (adhesions, limited visibility, bleeding and anatomic variations) is indispensable in terms of good professional conduct, and the best possible defence against allegations of negligence. Decisions to convert from laparoscopic to open surgery (including the timing) should also be documented clearly.

\section{Continuity of care and communication in and out of hospital}

One of the greatest appeals of laparoscopic surgery is the shorter recovery time, from which follows shorter hospital admission and early return to work and personal routines. Under normal conditions, this happy sequence is almost inevitably realised. Even patients with vague abdominal symptoms due to a low-volume bile leak may still plead to be discharged as soon as possible due to domestic pressures, hoping that those symptoms will resolve spontaneously. Medical aid plans may not fund the cost of an extended hospital stay, adding further pressure for day-after discharge where no obvious 'problem' is apparent.

Premature discharge from hospital along with broken continuity of care constitute two of the greatest pitfalls which impact on morbidity, the therapeutic relationship and the drive towards litigation. No extent of disappointment, domestic pressure or tedious negotiation with the patients' medical aid fund justifies the premature discharge of a patient who is nauseous, in pain, pyrexial or with reduced appetite 24 hours following laparoscopic cholecystectomy. However vague the symptoms or subtle the signs of a possible bile leak or bowel injury, no patient with either or both, should be sent home unless there is a clear pattern of recovery.

All patients need clear guidelines about postoperative follow up and self-care at home, and this is best summarised in a take-home letter which includes the surgeon's contact number and a clear message that enquiries or postoperative concerns can be communicated by SMS or WhatsApp. Without this precaution, patients with surgical complications will call their GP, or may report to an emergency unit at another hospital where their history in unknown. Delays aggravate the morbidity - and possible mortality - of iatrogenic injury, and patients who feel abandoned because they did not know where to take their postoperative problems are well-primed for litigation.

It is common practice for surgeons to take a few days off after an operating day and ask a colleague to 'keep an eye' while they are away. This is perfectly acceptable as long as there is comprehensive hand-over information provided, including mention of any technical challenges experienced during surgery, or risks or comorbidities which are specific to an individual patient. You, as the operating surgeon, need to be confident that your colleague will monitor your patients as carefully as his/her own, and not simply follow the 'weekend warrior' routine of a cheery wave and a greeting from the door of the ward before authorising discharge from hospital. Once again, the investment of a few handson minutes at the bedside and judicious inspection of the observation chart is worth a fortune in terms of accountable practice and litigation avoidance.

\section{What about when things go wrong}

Whether the iatrogenic BDI is recognised intraoperatively or only during the postoperative period, it is common wisdom that the 'injuring' surgeon should perform only the most basic drainage procedure, avoid the temptation to embark on any nature of repair, and enlist the expertise of a hepato-biliary sub-specialist to manage the patient further. There are 2 good reasons for this strategy quite apart from the specific issue of 
the technical expertise; firstly, substantive complications are upsetting to even the most confident practitioner and clinical judgment inevitably becomes clouded to some degree; secondly, the very act of enlisting - or even stepping aside for - a more seasoned 'pair of hands' sends a strong message of professional accountability to the patient. The notion that the injuring surgeon is trying to cover his/her tracks by attempting to repair the injury alone is highly contagious. To paraphrase the old English proverb: "The road to litigation is paved with many a good intention."

\section{Talking about injury and what lies ahead}

As with any surgical complication, the next step necessary after iatrogenic injury is possibly the most difficult. However, an explanation of what went wrong (where there is a definitive diagnosis of injury) or what may be going wrong (suspected injury) needs to be offered frankly, in nontechnical terms, and as soon as the patient has recovered from the procedure and is able to sensibly digest the information. The longer an injured patient lies in bed bedevilled by uncertainty, informed only by random bits of nursing chatter in the corridor, the sooner trust is displaced by anger and suspicion, and damage control becomes a steep hill to climb.

Your conversation with the injured patient should also include a roadmap of investigations and procedures to follow, all in comprehensible lay-terminology, and an open offer to convey the same information to significant family members. A sincere apology for the additional inconvenience and discomfort attendant on the complication and its cure will convey empathy and professionalism to the patient, and to some extent at least reduce the emotional ballast which every decent surgeon carries after a negative outcome. An apology is not an admission of guilt. The only possible admission of guilt, which is not generally recommended, is to blurt out: "I cut your common duct and it's all my fault!"

In a survey of plaintiffs conducted by solicitors in the UK, Vincent reported that $90 \%$ of 227 injured patients who were in the active process of suing their doctors for alleged malpractice expressed feelings of anger. ${ }^{8}$ Interestingly, he also reported that the same percentage of patients had decided to litigate because they simply "wanted an explanation" (of what had gone wrong). Thirty-seven per cent of the same patient sample indicated - albeit in retrospect - that an explanation and an apology for what had gone wrong would have steered them away from litigation.

The next step is to inform your medical malpractice indemnifier of the risk that litigation may be pursued in the future. Their advisors will guide you through the correct process to be followed.

\section{What not to do}

In addition to the noble but disastrous mea culpa referred to in the preceding paragraph, the surgeon should steer clear of any heated discussion with patients who react angrily to the news of iatrogenic injury. Never rise to the bait. Hear the patient out, answer what questions you can, and do your best to reassure. If the subject is raised about additional healthcare costs, offer to liaise with the medical insurer and to motivate for maximum cover, but never offer to offset the costs yourself, as that will almost certainly be interpreted as a sop to avoid full accountability, and will be launched at you like a nuclear warhead by the patient's counsel in the event of a trial.

Surgeons in state practice should not delegate the 'difficult conversation' to a junior colleague, particularly one who was not even present at the operation. Awkward ill-informed explanations from an embarrassed intern or registrar are simply fuel to the flame.

If you should at a later date receive a written complaint about the iatrogenic injury, do not respond yourself in the heat of the moment. Notify your employer or medical indemnifier (if you have not done so already), and let them advise you on the appropriate response.

\section{And if the patient sues you for damages}

From the medical practitioner's perspective, litigation is tedious, emotionally draining and takes forever to resolve. It drags us into a strange and arcane world where the language is foreign, your ex-patient is now your adversary, and lawyers may be ruthless. Even patients who yearn for their 'day in court' are usually emotionally exhausted by the time they enter the witness box. Win or lose, I can honestly say that I have never seen a medical malpractice plaintiff leave the court smiling. In simple terms, this prolonged process is pure unmitigated misery for everyone, except the lawyers. None of this even remotely justifies a retreat into the murky realm of defensive medicine which only guarantees to widen the rift between doctors and patients. Rather, and as the most effective redoubt against litigation, I would urge and encourage attention to the well-established basic principles of unrushed, ethical, and carefully documented clinical practice as the best way to stay out of 'big trouble'.

\section{Disclosure}

The author migrated from general surgery in 1987 and has never performed a single laparoscopic procedure on animal or human.

\section{REFERENCES}

1. Perera MT, Silva MA, Shah AJ, et al. Risk factors for litigation following major transectional bile duct injury at laparoscopic cholecystectomy. World J Surg. 2010;34:2635-41.

2. Roy PG, Soonawalla ZF, Grant HW. Medicolegal costs of bile duct injuries incurred during laparoscopic cholecystectomy. HPB. 2009;11:130-4.

3. Malherbe J. Counting the cost: The consequences of increased medical malpractice litigation in South Africa. S Afr Med J. 2013;103:83-4.

4. The Contingency Fees 1997 (Act 66 of 1997). Published as Government Notice R547 in Government Gazette Vol 20009 of 23 April 1999.

5. Whitehouse S. The risks of laparoscopic surgery. MPS Casebook 2012;20:7-9.

6. The National Health 2003 (Act 61 of 2003). Published as Government Notice 869 in Government Gazette Vol. 26595; 23 Jul 2004.

7. De Reuver PR, Wind J, Cremers JE, et al. Litigation after laparoscopic cholecystectomy: An evaluation of the Dutch arbitration system for medical malpractice. J Am Coll Surg. 2008;206:328-34.

8. Vincent C, Young M, Phillips A. Why do people sue doctors? A study of patients and relatives taking legal action. Lancet. 1994;343:1609-13. 